\title{
Increased isoprostane and prostaglandin are prominent in neurons in Alzheimer disease
}

\author{
Gemma Casadesus ${ }^{1}$, Mark A Smith ${ }^{2}$, Samar Basu ${ }^{3}$, Jing Hua ${ }^{2}$, \\ Dae E Capobianco ${ }^{2}$, Sandra L Siedlak², Xiongwei Zhu*2 and George Perry*2,4
}

\author{
Address: ${ }^{1}$ Department of Neuroscience, Case Western Reserve University, Cleveland, Ohio, USA, ${ }^{2}$ Department of Pathology, Case Western Reserve \\ University, Cleveland, Ohio, USA, ${ }^{3}$ Faculty of Medicine, Uppsala University, Uppsala, Sweden and ${ }^{4}$ College of Sciences, University of Texas at San \\ Antonio, Texas, USA \\ Email: Gemma Casadesus - gxc40@case.edu; Mark A Smith - mark.smith@case.edu; Samar Basu - Samar.Basu@geriatrik.uu.se; \\ Jing Hua - jing.hua@case.edu; Dae E Capobianco - dae.capobianco@case.edu; Sandra L Siedlak - sandra.siedlak@case.edu; \\ Xiongwei Zhu* - xiongwei.zhu@case.edu; George Perry* - george.perry@utsa.edu \\ * Corresponding authors
}

Published: 22 January 2007

Molecular Neurodegeneration 2007, 2:2 doi:10.1/86/1750-1326-2-2
Received: 09 November 2006

Accepted: 22 January 2007

This article is available from: http://www.molecularneurodegeneration.com/content/2/I/2

(C) 2007 Casadesus et al; licensee BioMed Central Ltd.

This is an Open Access article distributed under the terms of the Creative Commons Attribution License (http://creativecommons.org/licenses/by/2.0), which permits unrestricted use, distribution, and reproduction in any medium, provided the original work is properly cited.

\begin{abstract}
Background: Inflammation and oxidative stress are both involved in the pathogenesis of Alzheimer disease and have been shown to be reciprocally linked. One group of molecules that have been directly associated with inflammation and the production of free radicals are the prostaglandin I3, I4-dihydro I5-keto $\mathrm{PGF}_{2 \alpha}$ and the isoprostane 8-iso-PGF $2 \alpha$.

Results: To further delineate the role of inflammatory and oxidative parameters in Alzheimer disease, in this study we evaluated the amount and localization of 13,14-dihydro I5-keto PGF ${ }_{2 \alpha}$ and 8-iso-PGF ${ }_{2 \alpha}$ in hippocampal post mortem tissue samples from age-matched Alzheimer disease and control patients. Our results demonstrate increased levels of 13,I4-dihydro I5-keto $\mathrm{PGF}_{2 \alpha}$ and 8iso-PGF $2 \alpha$ in the hippocampal pyramidal neurons of Alzheimer disease patients when compared to control patients.

Conclusion: These data not only support the shared mechanistic involvement of free radical damage and inflammation in Alzheimer disease, but also indicate that multiple pathogenic "hits" are likely necessary for both the development and propagation of Alzheimer disease.
\end{abstract}

\section{Background}

Alzheimer disease (AD) is the leading cause of senile dementia, with a prevalence that is directly related to age [1]. Over 4 million individuals are currently affected with the disease in the United States alone and this number is projected to increase to 14 million by 2050 [2]. At the present time, therapeutic management of the disease is primarily focused on palliative treatment of the symptoms rather than forestalling the progression of the disease [3] and the major obstacle in designing a rationale for therapeutic targets is our incomplete understanding of pathogenesis. To this end, it is imperative that the mechanistic hallmarks of this disease are established.

The tight association between aging and $\mathrm{AD}$ has led the field to propose oxidative stress as a major mechanism responsible for the onset and progression of AD [4]. Physiologically, the production of reactive oxygen species (ROS) is found in all aerobic organisms and arises from the secondary production of superoxide, hydrogen perox- 
ide and the reaction of superoxide with nitric oxide (peroxynitrite) during metabolic and extra-metabolic processes of all cells. In $\mathrm{AD}$, the excess formation of ROS is evident by signature reactions with critical biological molecules yielding damage to every category of biomacromolecules: sugars, lipids, proteins and nucleic acids [4]. That such oxidative damage occurs as one of the earliest aberrations in the disease indicates a major role of free radical damage in both etiology and pathogenesis.

In addition to direct oxidation damage of cellular macromolecules, free radical formation can also lead to damage indirectly by activating other harmful mechanisms such as inflammation [5]. In this regard, oxidative stress and inflammation are reciprocally linked such that inflammatory processes lead to increases in ROS production [6] and vice versa [7]. Given this interdependence, it is perhaps not surprising that ROS and inflammation can both be attenuated by individually targeted treatments, i.e., antioxidant or non-steroidal anti-inflammatory drug treatment $[6,8,9]$.

Of note in this regard, epidemiological studies indicate a reduced risk of $\mathrm{AD}$ among users of anti-inflammatory drugs. Animal studies demonstrate that the capacity of non-steroidal anti-inflammatory drugs (NSAIDs) is to reduce the amount of plaque formation in mouse models of the disease. NSAIDs work mainly through the inhibition of cyclooxygenase, which is a critical component of the inflammatory response [10]. Therefore, anti-inflammatory drugs such as NSAIDs have become the focus of several new treatment strategies $[11,12]$.

Like oxidative stress, inflammatory processes have been associated with $\mathrm{AD}$ and thought to play a major role in its onset and progression. In this regard, cytokines, such as interleukin-1 (IL-1), interleukin-6 (IL-6), tumor necrosis factor $\alpha$ (TNF- $\alpha$ ) and transforming growth factor beta (TGF- $\beta$ ) are all affected and likely contribute to the inflammatory activation of microglia and astroglia [13].

One group of novel molecules that establish the link between inflammation and oxidative stress are prostaglandins and isoprostanes, respectively $[14,15]$. Prostaglandins are a group of 20-carbon containing hormonelike fatty acid derivatives that are produced by catalyzed cyclooxygenase of the arachidonic acid and localized to various tissues in the body [16]. Prostaglandins are important mediators of the inflammatory process $[17,18]$ and 13,14-dihydro 15-keto PGF $2 \alpha$ a major metabolite of prostaglandin $\mathrm{F}_{2 \alpha}\left(\mathrm{PGF}_{2 \alpha}\right)$, is shown to be a potent indicator of in vivo cyclooxygenase (COX)-mediated inflammatory processes [19-22]. On the other hand, $\mathrm{F}_{2}$-isoprostanes, prostaglandin-like novel compounds are formed during free-radical catalyzed, non-enzymatic peroxidation of ara- chidonic acid [23] and, as such, considered to be reliable indicators of oxidative stress in vivo $[14,22,24]$.

With regard to $\mathrm{AD}$, some studies have shown increased F2-isoprostane levels in plasma or urine of $\mathrm{AD}$ patients compared to age-matched controls [25-27], however these findings remain controversial [28-30]. In addition, increased CSF levels of $\mathrm{F}_{2}$-isoprostanes have also been shown in AD patients $[25,28,31-33]$, which, importantly, can be suppressed by antioxidant treatment [34]. While levels within the brain have been found to be increased in regions vulnerable to the disease [35,36], controversy remains as to localization (i.e., glia or disease-vulnerable neurons) and whether increased $\mathrm{F}_{2}$-isoprostane levels in $\mathrm{AD}$ are associated with the progression of the disease or rather are simply markers of increased gliosis [30]. In an attempt to clarify this controversy and accurately localize the presence of both $\mathrm{PGF}_{2 \alpha}$ and $\mathrm{F}_{2}$-isoprostanes, we used an immunohistochemical method to examine both the levels and the subcellular localization of $\mathrm{PGF}_{2 \alpha}$ and $\mathrm{F}_{2}$-isoprostanes in the $\mathrm{AD}$ brain.

\section{Results}

Detailed microscopic localization of 8 -iso-PGF $2 \alpha$ and 13, 14-dihydro 15-keto $\mathrm{PGF}_{2 \alpha}$ in the $\mathrm{AD}$ cases revealed strong labeling of the cytoplasm of neurons, when compared to age-matched control cases (Figure 1). Neuronal populations principally affected were large pyramidal neurons of the hippocampal formation (CA-1, CA-2, and CA-3/4), subiculum, pre- $\alpha$ layer of the entorhinal cortex, and cerebral neocortex. While neurons affected by neurofibrillary pathology showed labeling with both antibodies, there was no predilection for pathologically altered neurons, as the majority of the labeling occurred in the perikaryal cytoplasm of morphologically normal pyramidal neurons. Dystrophic neurites and neuropil threads were not observed with 13,14-dihydro 15-keto $\mathrm{PGF}_{2 \alpha}$ and 8-iso$\mathrm{PGF}_{2 \alpha}$ antibodies. No labeling of neuritic plaques or parenchymal amyloid- $\beta$ deposits could be discerned. In addition to neuronal immunoreactivity, immunolabeling of reactive astrocytes, generally in parallel with the perinuclear accumulations of glial filaments, was noted diffusely in some sections. Blood vessels, ependymal cells, and choroid plexus epithelium showed no significant immunoreactivity. Demonstrating the specificities of our findings, antibodies directed against porcine-thyroglobulin linked 13,14-dihydro 15-keto $\mathrm{PGF}_{2 \alpha}$ and 8 -iso-PGF $2 \alpha$ revealed very similar staining patterns of increased neuronal as well as glial cells in AD cases. Moreover, omission of the primary antibodies completely abolished immunoreactivity (data not shown).

Quantification of the relative densities of pyramidal neurons stained revealed a statistically significant increase in the immunoreactivities for 8 -iso- PGF $_{2 \alpha}(\mathrm{p}<0.01)$ and 

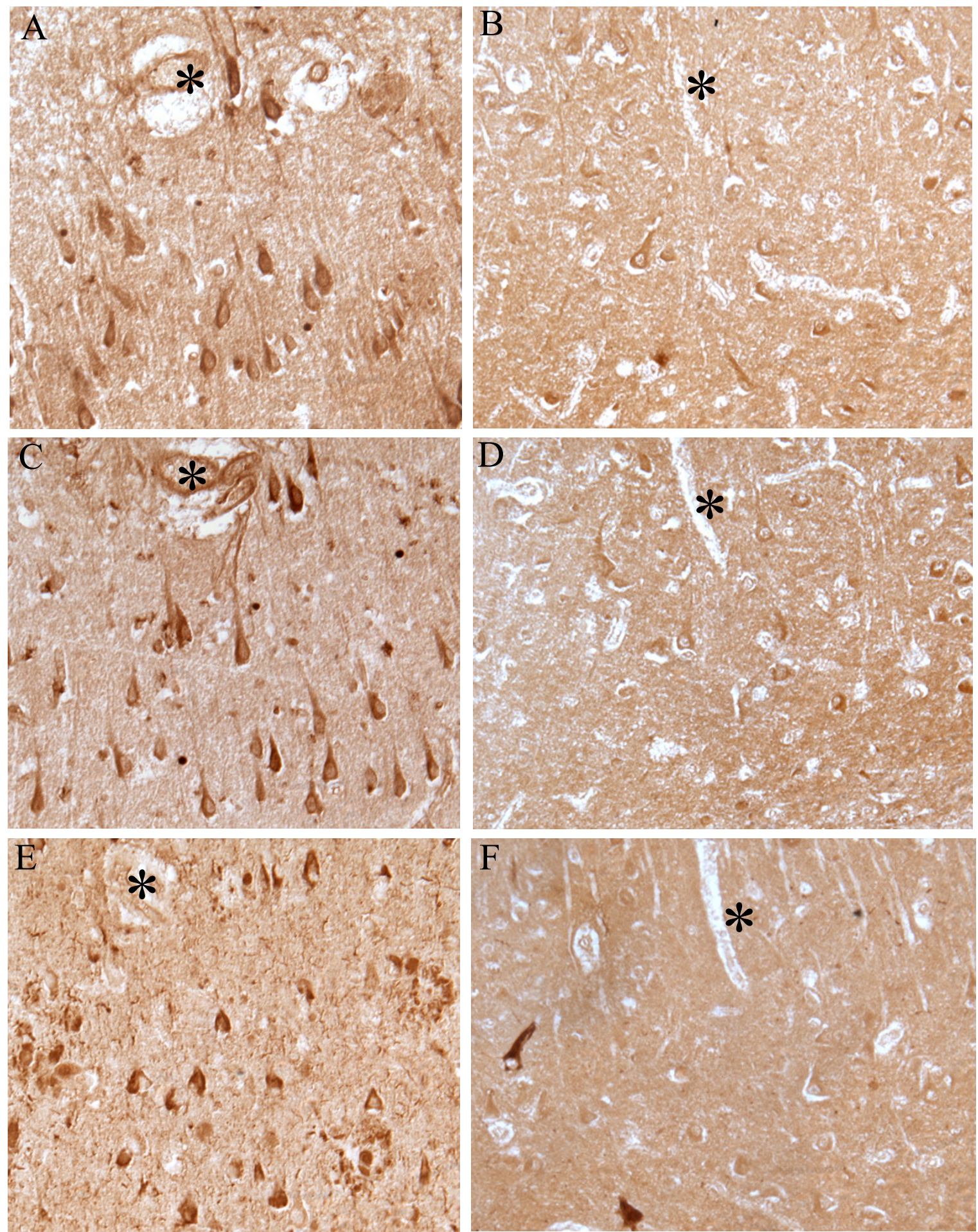

\section{Figure I}

Isoprostanes localization in $A D$ and control brain. In adjacent serial sections of hippocampus of $A D$ cases, neurons are intensely labeled with antisera against 13, I4-dihydro I5-keto $\mathrm{PGF}_{2 \alpha}(\mathrm{A})$ and 8-iso-PGF ${ }_{2 \alpha}(\mathrm{C})$. AT8 recognizes NFT in the same field (E). In adjacent serial sections from an age-matched control, neuronal levels of 13,14-dihydro I5-keto PGF ${ }_{2 \alpha}$ (B) and 8-isoPGF $_{2 \alpha}$ (D) are significantly lower. Only a few NFT recognized by AT8 are present in the control. $\left.{ }^{*}\right)$ marks landmark vessels in series $(A, C, E)$ and $(B, D, F)$. Scale bar $=50 \mu \mathrm{m}$. 
$\mathrm{PGF}_{2 \alpha}$ metabolite $(\mathrm{p}<0.001)$ in $\mathrm{AD}$ cases (Figure $\left.2 \mathrm{~A}\right)$. In the same three fields on adjacent serial sections stained for phosphorylated tau, the number of immunostained neurofibrillary tangles (NFT) was quantified. In the AD cases, the number of NFT within the three fields analyzed ranged from 31-293 NFT, mean of 121. Eight of the 10 age-matched control cases contained small numbers of AT8-positive NFT, ranging from 3-43 in the fields analyzed, mean of 20.3. Relative neuronal density of 8-iso$\mathrm{PGF}_{2 \alpha}$ or $\mathrm{PGF}_{2 \alpha}$ metabolite in the AD cases showed no correlation with the number of NFT $(r=0.12)$, while the control cases showed a significant positive correlation $(\mathrm{r}=$ .68 ; $\mathrm{p}<0.05$ ) of NFT numbers with 8 -iso- $\mathrm{PGF}_{2 \alpha}$ (Fig 2B). No significant correlation was noted between levels of 13,14-dihydro 15-keto $\mathrm{PGF}_{2 \alpha}$ and 8 -iso-PGF $2 \alpha$ with age in either the control or $\mathrm{AD}$ cases.

\section{Discussion}

The data presented in this study shows both $\mathrm{PGF}_{2 \alpha}$ and $\mathrm{F}_{2}-$ isoprostanes are increased in hippocampal tissue collected from $\mathrm{AD}$ patients compared to non-AD patients, indicating that brain inflammation and oxidative stress are significantly higher in $\mathrm{AD}$ compared to the agedmatched controls. This study is the first of its kind to report an increased level of a prostaglandin $\mathrm{F}_{2 \alpha}$-metabolite, which corresponds to the level of the COX-mediated primary prostaglandin $\mathrm{F}_{2 \alpha^{\prime}}$ in the brains of individuals affected by AD. This data certainly augments the work of Ho et al, who carefully characterized the appearance and progression of neuronal accumulation of COX-2 as both a function of clinical course of the disease as well as within different neuronal populations of the hippocampus [37]. Their findings highlight the COX-2 involvement early in the disease course which provides a reasonable and prudent target for therapeutics such as NSAIDS. This is extremely relevant to the current work on prostaglandins, whose appearance coincides with the cellular location and development of pathology as seen with COX-2.

Prostaglandins are well-known mediators of inflammation [17]. 15-Keto-dihydro-PGF $2 \alpha^{\prime}$ a metabolite of bioactive $\mathrm{PGF}_{2 \alpha}$ metabolized through 13,14-dihydro 15-keto $\mathrm{PGF}_{2 \alpha}$ dehydrogenases in most of the tissues in the body is a potent indicator of in vivo inflammatory processes [19-22]. Thus, the results from this study suggest a local ongoing COX-related inflammatory process among patients with $\mathrm{AD}$, which possibly plays a major role in the onset or progression of the disease. In addition, $\mathrm{PGF}_{2 \alpha}$ is shown to be a potent vasoconstrictive compound [38] which also may play a role in the progression of $\mathrm{AD}$ in which vascular degeneration is a characteristic [4]. Notably, amyloid- $\beta$ itself can act as a pro-inflammatory agent causing the activation of many of the inflammatory components, including glial activation $[39,40]$ and, in somewhat of a feedforward manner, cyclooxygenases potentiate the generation of amyloid- $\beta$ [41]. However, it is important to note that our findings revealed little correlation between amyloid and 13,14-dihydro 15-keto $\mathrm{PGF}_{2 \alpha}$ and 8-iso-PGF $\mathrm{PG}_{2 \alpha}$. Similarly, while no correlation was found with phosphorylated tau among the AD cases, a positive correlation was seen among the controls, indicating the inflammatory response as an early change. Clinical data on the mental status of the control cases used in this study was not available, therefore further analysis using clinically followed cases of mild cognitive impairment would be required to faithfully answer this question. These findings are not only consistent with findings of other oxidative adducts $[42,43]$, but also emphasize the often different properties of amyloid- $\beta$ and phosphorylated tau in vivo compared to in vitro $[44,45]$.

Another novel finding in this study is that the levels of $\mathrm{F}_{2}$ isoprostanes are increased in hippocampal sections from patients with $\mathrm{AD}$ as compared to the control subjects. These findings are in accordance with previous mass spectrometry studies demonstrating increased levels of $\mathrm{F}_{2}$-isoprostanes in the AD brain [46]. Our study has now shown the specific localization of these proteins in the AD brain demonstrating that these adducts strikingly localize to vulnerable neurons in the disease as well as other cellular types like glia, often associated with inflammatory responses. $\mathrm{F}_{2}$-isoprostanes are now regarded as one of the most reliable indicators of oxidative stress in vivo $[15,47]$. Elevated level of isoprostanes has been shown in CSF and brain tissue previously $[35,48]$, however, there are controversies regarding the levels of isoprostanes in the plasma or urine [15]. One study describes higher levels of isoprostanes in the plasma and urine [25], while others do not $[28,29]$ The accumulation of both $\mathrm{PGF}_{2 \alpha}$ and $\mathrm{F}_{2}$-isoprostanes in cerebral tissues collected from $\mathrm{AD}$ are an unique finding since both of these compounds possess extremely short half-lives $[16,49,50]$. In this regard, elevations of these compounds are seen only for a short period of time in experimental acute inflammation protocols (e.g., septic shock) following cardiac arrest or cardio pulmonary bypass surgery, which rapidly decrease to the initial basal levels [19,21,51]. Nevertheless, a more persistent rise of basal levels of these compounds is observed during chronic inflammation such as in various rheumatic diseases and type 2 diabetes [15]. Therefore, as previously suggested [52], the levels of oxidative stress are likely low and chronic in nature.

Notably, and in addition to being excellent markers of inflammation, both $\mathrm{PGF}_{2 \alpha}$ and $\mathrm{F}_{2}$-isoprostanes (mainly 8iso-PGF ${ }_{2 \alpha}$ ) possess independent bioactive properties. That no age related increase was found in either the normal or disease tissue suggests a more direct role in disease pathogenesis. In this regard, $\mathrm{PGF}_{2 \alpha}$ and $\mathrm{F}_{2}$-isoprostanes (mainly 8 -iso-PGF $2 \alpha$ ) are potent vasoconstrictive agents, and 

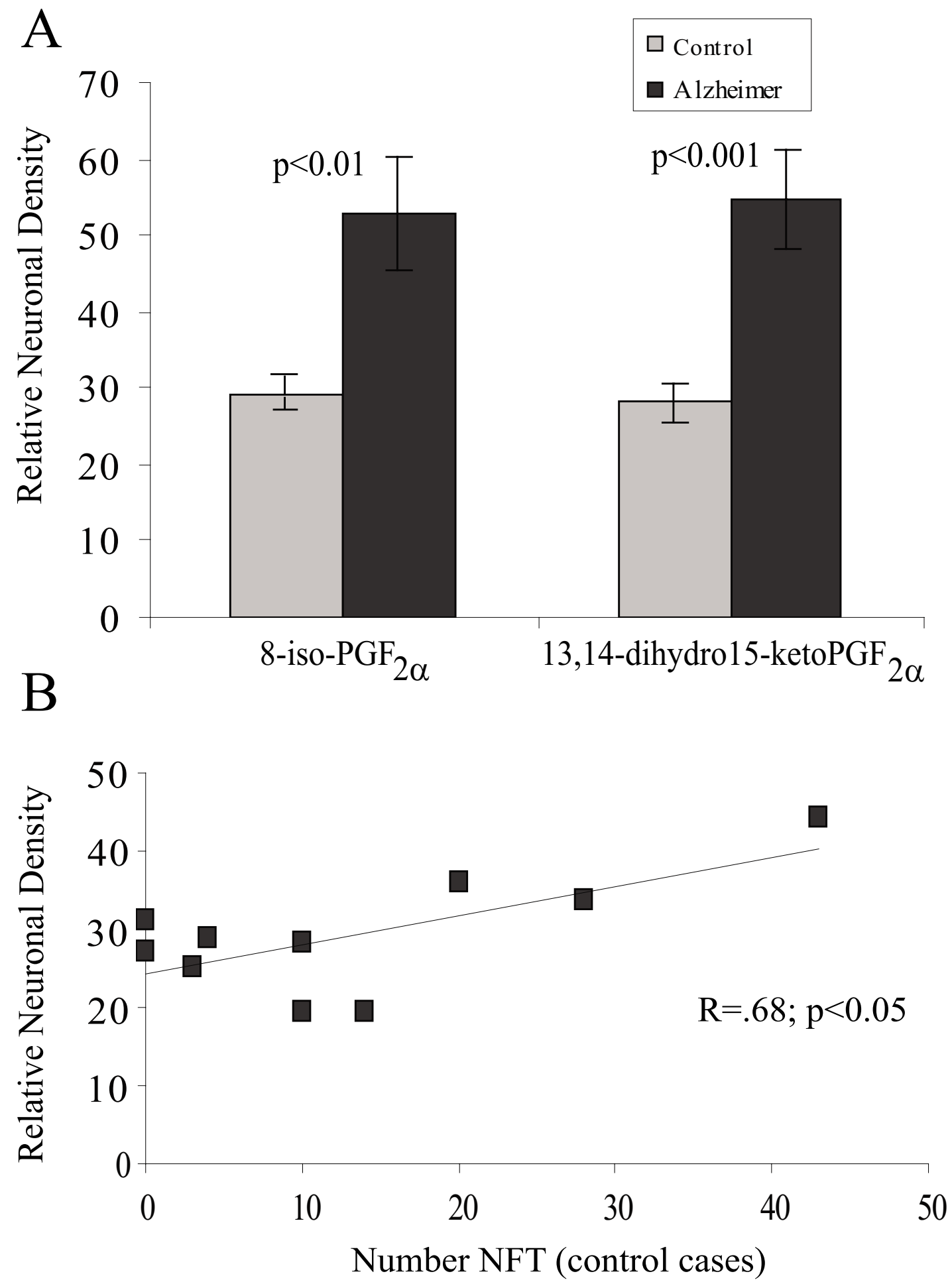

\section{Figure 2}

Quantification of neuronal levels of isoprostanes. A. Computer assisted image analysis reveals pyramidal neurons from cases of $A D(n=10)$ reveal significantly higher levels of 8-iso-PGF $2 \alpha(p<0.0 I)$ and I3, I4-dihydro I5-keto PGF $2 \alpha(p<0.00 I)$ than aged controls $(n=10)$. Mann-Whitney U-test. Data shown expresses mean $+/-$ SEM. $B$. In the aged control cases, neuronal levels of 8-iso-PGF $2 \alpha$ are significantly correlated with the numbers of AT8-positive NFT. 
$\mathrm{PGF}_{2 \alpha}$ is a well known mediator of pain and inflammation [17]. Further it has recently been shown that 8-iso$\mathrm{PGF}_{2 \alpha}$ can induce $\mathrm{PGF}_{2 \alpha}$ release and thereby inflammatory responses in rabbits [15]. Therefore, the accumulation of $\mathrm{PGF}_{2 \alpha}$ and $\mathrm{F}_{2}$-isoprostanes in the cerebral tissues not only indicates the presence of massive inflammation in the $\mathrm{AD}$ brain but also highlights the impact that these compounds could have independent bioactive entities, where a chronic accumulation of these compounds in the brain could further worsen the status of inflammation and oxidative stress and thus the pathophysiology of the disease. These latter findings together with the current findings of in situ localization of $\mathrm{F}_{2}$-isoprostanes in the hippocampal or cortical tissue samples from $\mathrm{AD}$ patients further supports the notion that locally involved oxidative stress together with the inflammatory response is possibly one of the major mechanistic hallmarks of $\mathrm{AD}$ and therefore represent therapeutic intervention points of great potential. However, despite the apparent effectiveness for NSAIDs, which are COX inhibitors, and antioxidants on preventing the risk of developing $\mathrm{AD}$ consistently reported in epidemiology studies [53,54], clinical trials with these drugs demonstrate little to no effect in $\mathrm{AD}$ patients [55]. These findings highlight the importance of early interruption of pathogenic processes, consistent with our finding of a positive correlation between neuronal 8-iso-PGF ${ }_{2 \alpha}$ and NFT numbers in control cases but not in $\mathrm{AD}$ cases.

In conclusion, this study presents an accumulation of both prostaglandins and isoprostanes in the brain tissues of patients with $\mathrm{AD}$ which further advocates for importance of inflammation and oxidative stress in this disease and treatment strategies that counteract inflammatory processes and oxidative stress simultaneously.

\section{Methods \\ Tissue}

Hippocampal and cortical tissue samples were obtained post mortem from patients with histopathologically confirmed $A D(n=21$, ages 61-96 years, mean $=80.8$ years $)$. Control cases used in this study included 3 young (ages 17,23 , and 43 years) and 13 aged-matched controls (ages 60-91 years, mean 72.9 years) with similar post mortem intervals (AD: 3-37 hr, mean 14.3 hour; controls: 3-48 $\mathrm{hr}$, mean $19.1 \mathrm{hr}$ ). All cases were categorized based on clinical and pathological criteria established by CERAD and NIA consensus panel $[56,57]$. From the clinical reports available to us, we found no obvious differences in agonal status or other potential confounders between the groups. Tissue was fixed in methacarn (methanol: chloroform: acetic acid; $6: 3: 1 \mathrm{v} / \mathrm{v} / \mathrm{v}$ ) at $4{ }^{\circ} \mathrm{C}$ overnight. Following fixation, tissue was dehydrated through ascending ethanol, embedded in paraffin, and $6-\mu \mathrm{m}$ sections were placed on silane-coated slides (Sigma, St. Louis, MO, USA).

\section{Immunocytochemistry}

Tissue sections were de-paraffinized in xylene, hydrated through descending ethanol, and endogenous peroxidase activity quenched by a 30 min incubation in 3\% hydrogen peroxide in methanol. Non-specific binding sites were blocked by a 30 min incubation in 10\% normal goat serum. Tissue sections were immunostained using the peroxidase/anti-peroxidase method with 3-3'-diaminobenzidine as co-substrate as previously described [5]. Antibodies used were: 1) rabbit polyclonal antibody to free 13,14-dihydro 15-keto $\mathrm{PGF}_{2 \alpha}$ [22]; 2) rabbit polyclonal antibody to free 8-iso- $\mathrm{PGF}_{2 \alpha}[58] ; 3$ ) rabbit polyclonal antibody to free 8-iso-PGF ${ }_{2 \alpha}$ conjugated to porcine thyroglobulin (Assay Designs, MI); and 4) rabbit polyclonal antibody to free 13, 14-dihydro 15-keto $\mathrm{PGF}_{2 \alpha}$ (Cayman Chemical, MI). Sections were also immunostained with a monoclonal mouse antibody AT8, which recognizes phosphorylated tau (Ser202/Thr205) (Pierce, Rockford, IL) to identify the location of pathological structures. Control experiments included omission of primary antisera.

\section{Quantification}

Quantification of 13, 14-dihydro 15-keto $\mathrm{PGF}_{2 \alpha}$ and 8iso-PGF ${ }_{2 \alpha}$ protein immunoreactivity was performed as previously described [43]. The cases used included $10 \mathrm{AD}$ (ages 65-87 years) and 10 age-matched controls (ages 67-82 years) that were randomly selected and stained with the same antisera $[22,58]$ at the same time. Digital images were taken with an Axiocam camera (KS300, Zeiss, Munchen-Hallbergmoss, Germany) and compatible quantification software (Axiovision, Carl Zeiss Vision $\mathrm{GmbH}$, Munchen-Hallbergmoss, Germany) used to determine the mean staining intensity of pyramidal neurons in the CA1/CA2 region of the hippocampus. Briefly, using the $20 \times$ objective, 3 fields were selected and the software outlined the immunostained structures and measured the intensity. The intensity of all unstained areas within each fields are determined as the background levels. In those cases where neuronal staining was at the background level and the software unable to delineate the cell bodies, all pyramidal neurons within each field, where nuclei were visible were outlined manually and measured as above. Mean neuronal intensities for each case were determined and because the $\mathrm{n}$ numbers were relatively small, the Mann-Whitney test applied (SigmaStat).

In the same fields on adjacent sections immunostained with monoclonal anti-phosphorylated tau (AT8), the numbers of NFTs were counted. Correlations were determined between the mean level of neuronal prostaglandin and isoprostane with the number of NFTs in the cases. 


\section{Competing interests}

The author(s) declare that they have no competing interests.

\section{Authors' contributions}

GC, JH, DC, SLS collected the data. GC participated in the design of the study and performed the statistical analysis. MAS, XZ, SB, and GP conceived of the study, and participated in its design and coordination and helped to draft the manuscript. All authors read and approved the final manuscript.

\section{Acknowledgements}

Work in the authors' laboratories is supported by National Institutes of Health, the Alzheimer's Association, and by Philip Morris USA Inc. and Philip Morris International.

\section{References}

I. Katzman R: Alzheimer's disease as an age-dependent disorder. Ciba Found Symp 1988, 134:69-85.

2. Larson EB, Kukull WA, Katzman RL: Cognitive impairment: dementia and Alzheimer's disease. Annu Rev Public Health 1992, 1 3:431-449.

3. Marlatt MW, Webber KM, Moreira PI, Lee HG, Casadesus G, Honda $\mathrm{K}$, Zhu X, Perry G, Smith MA: Therapeutic opportunities in Alzheimer disease: one for all or all for one? Curr Med Chem 2005, I 2(I0): I|37-I| 47

4. Perry G, Castellani RJ, Hirai K, Smith MA: Reactive oxygen species mediate cellular damage in Alzheimer disease. J Alzheimers Dis 1998, I(I):45-55.

5. Smith MA, Richey Harris PL, Sayre LM, Beckman JS, Perry G: Widespread peroxynitrite-mediated damage in Alzheimer's disease. J Neurosci 1997, I7(8):2653-2657.

6. Wang T, Qin L, Liu B, Liu Y, Wilson B, Eling TE, Langenbach R, Taniura $S$, Hong JS: Role of reactive oxygen species in LPS-induced production of prostaglandin E2 in microglia. J Neurochem 2004, 88(4):939-947.

7. Qin L, Liu Y, Wang T, Wei SJ, Block ML, Wilson B, Liu B, Hong JS: NADPH oxidase mediates lipopolysaccharide-induced neurotoxicity and proinflammatory gene expression in activated microglia. J Biol Chem 2004, 279(2): |4I5-|42I.

8. Hou RC, Huang HM, Tzen JT, Jeng KC: Protective effects of sesamin and sesamolin on hypoxic neuronal and PCI 2 cells. J Neurosci Res 2003, 74(I): I23-133.

9. Godbout JP, Berg BM, Kelley KW, Johnson RW: alpha-Tocopherol reduces lipopolysaccharide-induced peroxide radical formation and interleukin-6 secretion in primary murine microglia and in brain. J Neuroimmunol 2004, I 49(1-2): $101-109$.

10. Sung S, Yao Y, Uryu K, Yang H, Lee VM, Trojanowski JQ, Pratico D: Early vitamin $E$ supplementation in young but not aged mice reduces Abeta levels and amyloid deposition in a transgenic model of Alzheimer's disease. FASEB J 2004, I 8(2):323-325.

II. Gasparini L, Rusconi L, Xu H, del Soldato P, Ongini E: Modulation of beta-amyloid metabolism by non-steroidal anti-inflammatory drugs in neuronal cell cultures. J Neurochem 2004, 88(2):337-348.

12. Imbimbo BP: The potential role of non-steroidal anti-inflammatory drugs in treating Alzheimer's disease. Expert Opin Investig Drugs 2004, I3(I I): I469-I48I.

13. Hull M, Lieb K, Fiebich BL: Pathways of inflammatory activation in Alzheimer's disease: potential targets for disease modifying drugs. Curr Med Chem 2002, 9(I):83-88.

14. Basu S: Carbon tetrachloride-induced lipid peroxidation: eicosanoid formation and their regulation by antioxidant nutrients. Toxicology 2003, 189(1-2): I|3-127.

15. Basu S: Isoprostanes: novel bioactive products of lipid peroxidation. Free Radic Res 2004, 38(2): $105-122$.

16. Samuelsson B: Prostaglandins and thromboxanes. Recent Prog Horm Res 1978, 34:239-258.
17. Vane JR: Prostaglandins as mediators of inflammation. In Adv Prostaglandin Thromboxane Res Edited by: Samuelsson B, Paoletti R. New York, Raven Press; 1976.

18. Willoughby DA: Heberden Oration, 1974. Human arthritis applied to animal models. Towards a better therapy. Ann Rheum Dis 1975, 34(6):47I-478.

19. Basu S, Nozari A, Liu XL, Rubertsson S, Wiklund L: Development of a novel biomarker of free radical damage in reperfusion injury after cardiac arrest. FEBS Lett 2000, 470(I): I-6.

20. Mutschler DK, Eriksson MB, Wikstrom BG, Lind L, Larsson A, Bergren-Kiiski R, Lagrange A, Nordgren A, Basu S: Microdialysis-evaluated myocardial cyclooxygenase-mediated inflammation and early circulatory depression in porcine endotoxemia. Crit Care Med 2003, 3 I(6): 1780-1785.

21. Basu S, Eriksson M: Oxidative injury and survival during endotoxemia. FEBS Lett 1998, 438(3): 159-160.

22. Basu S: Radioimmunoassay of 15-keto-13,14-dihydro-prostaglandin F2alpha: an index for inflammation via cyclooxygenase catalysed lipid peroxidation. Prostaglandins Leukot Essent Fatty Acids 1998, 58(5):347-352.

23. Morrow JD, Hill KE, Burk RF, Nammour TM, Badr KF, Roberts LJ 2nd: A series of prostaglandin $F 2$-like compounds are produced in vivo in humans by a non-cyclooxygenase, free radical-catalyzed mechanism. Proc Natl Acad Sci U S A 1990, 87(23):9383-9387.

24. Basu S, Helmersson J: Factors regulating isoprostane formation in vivo. Antioxid Redox Signal 2005, 7(I-2):22I-235.

25. Pratico D, Clark CM, Lee VM, Trojanowski JQ, Rokach J, FitzGerald GA: Increased 8, I 2-iso-iPF2alpha-VI in Alzheimer's disease: correlation of a noninvasive index of lipid peroxidation with disease severity. Ann Neurol 2000, 48(5):809-8I 2.

26. Tuppo EE, Forman LJ, Spur BW, Chan-Ting RE, Chopra A, Cavalieri TA: Sign of lipid peroxidation as measured in the urine of patients with probable Alzheimer's disease. Brain Res Bull 200I, 54(5):565-568.

27. Kim KM, Jung BH, Paeng KJ, Kim I, Chung BC: Increased urinary $F(2)$-isoprostanes levels in the patients with Alzheimer's disease. Brain Res Bull 2004, 64(I):47-5I.

28. Montine TJ, Shinobu L, Montine KS, Roberts LJ 2nd, Kowall NW, Beal MF, Morrow JD: No difference in plasma or urinary F2-isoprostanes among patients with Huntington's disease or Alzheimer's disease and controls. Ann Neurol 2000, 48(6):950.

29. Feillet-Coudray C, Tourtauchaux R, Niculescu M, Rock E, Tauveron I, Alexandre-Gouabau MC, Rayssiguier Y, Jalenques I, Mazur A: Plasma levels of 8-epiPGF2alpha, an in vivo marker of oxidative stress, are not affected by aging or Alzheimer's disease. Free Radic Biol Med 1999, 27(3-4):463-469.

30. Montine TJ, Quinn JF, Milatovic D, Silbert LC, Dang T, Sanchez S, Terry E, Roberts LJ 2nd, Kaye JA, Morrow JD: Peripheral F2-isoprostanes and F4-neuroprostanes are not increased in Alzheimer's disease. Ann Neurol 2002, 52(2): $175-179$.

31. Montine TJ, Beal MF, Cudkowicz ME, O'Donnell H, Margolin RA, McFarland L, Bachrach AF, Zackert WE, Roberts LJ, Morrow JD: Increased CSF F2-isoprostane concentration in probable AD. Neurology 1999, 52(3):562-565.

32. Montine TJ, Sidell KR, Crews BC, Markesbery WR, Marnett LJ, Roberts LJ 2nd, Morrow JD: Elevated CSF prostaglandin E2 levels in patients with probable AD. Neurology | 999, 53(7): | 495- | 498.

33. Pratico D, luliano L, Amerio G, Tang LX, Rokach J, Sabatino G, Violi F: Down's syndrome is associated with increased 8,12-isoiPF2alpha-VI levels: evidence for enhanced lipid peroxidation in vivo. Ann Neurol 2000, 48(5):795-798.

34. Souvignet C, Cracowski JL, Stanke-Labesque F, Bessard G: Are isoprostanes a clinical marker for antioxidant drug investigation? Fundam Clin Pharmacol 2000, I 4(I): I-I0.

35. Pratico D, V MYL, Trojanowski JQ, Rokach J, Fitzgerald GA: Increased F2-isoprostanes in Alzheimer's disease: evidence for enhanced lipid peroxidation in vivo. FASEB J 1998, I2(15): 1777-1783.

36. Reich EE, Markesbery WR, Roberts LJ 2nd, Swift LL, Morrow JD, Montine TJ: Quantification of F-ring and D-/E-ring isoprostanes and neuroprostanes in Alzheimer's disease. Adv Exp Med Biol 200I, 500:253-256.

37. Ho L, Purohit D, Haroutunian V, Luterman JD, Willis F, Naslund J, Buxbaum JD, Mohs RC, Aisen PS, Pasinetti GM: Neuronal cyclooxygenase 2 expression in the hippocampal formation as a 
function of the clinical progression of Alzheimer disease. Arch Neurol 200I, 58(3):487-492.

38. Bergstrom S: Prostaglandins: members of a new hormonal system. These physiologically very potent compounds of ubiquitous occurrence are formed from essential fatty acids. Science 1967, I57(787):382-391.

39. Tuppo EE, Arias HR: The role of inflammation in Alzheimer's disease. Int J Biochem Cell Biol 2005, 37(2):289-305.

40. Craft JM, Watterson DM, Van Eldik LJ: Human amyloid betainduced neuroinflammation is an early event in neurodegeneration. Glia 2006, 53(5):484-490.

4I. Oin W, Ho L, Pompl PN, Peng Y, Zhao Z, Xiang Z, Robakis NK, Shioi J, Suh J, Pasinetti GM: Cyclooxygenase (COX)-2 and COX-I potentiate beta-amyloid peptide generation through mechanisms that involve gamma-secretase activity. J Biol Chem 2003, 278(5 I):50970-50977.

42. Nunomura A, Perry G, Pappolla MA, Wade R, Hirai K, Chiba S, Smith $M A$ : RNA oxidation is a prominent feature of vulnerable neurons in Alzheimer's disease. J Neurosci 1999, 19(6): 1959-1964.

43. Nunomura A, Perry G, Aliev G, Hirai K, Takeda A, Balraj EK, Jones PK, Ghanbari H, Wataya T, Shimohama S, Chiba S, Atwood CS, Petersen RB, Smith MA: Oxidative damage is the earliest event in Alzheimer disease. I Neuropathol Exp Neurol 200I, 60(8):759-767.

44. Rottkamp CA, Atwood CS, Joseph JA, Nunomura A, Perry G, Smith MA: The state versus amyloid-beta: the trial of the most wanted criminal in Alzheimer disease. Peptides 2002, 23(7):|333-|34|.

45. Rottkamp CA, Raina AK, Zhu X, Gaier E, Bush Al, Atwood CS, Chevion M, Perry G, Smith MA: Redox-active iron mediates amyloid-beta toxicity. Free Radic Biol Med 200I, 30(4):447-450.

46. Bohnstedt KC, Karlberg B, Wahlund LO, Jonhagen ME, Basun H, Schmidt S: Determination of isoprostanes in urine samples from Alzheimer patients using porous graphitic carbon liquid chromatography-tandem mass spectrometry. Journal of chromatography 2003, 796(I): II-19.

47. Roberts LJ, Morrow JD: Measurement of F(2)-isoprostanes as an index of oxidative stress in vivo. Free Radic Biol Med 2000, 28(4):505-5।3.

48. Montine TJ, Beal MF, Robertson D, Cudkowicz ME, Biaggioni O'Donnell H, Zackert WE, Roberts LJ, Morrow JD: Cerebrospinal fluid F2-isoprostanes are elevated in Huntington's disease. Neurology 1999, 52(5): I I04-I I05.

49. Roberts LJ 2nd, Moore KP, Zackert WE, Oates JA, Morrow JD: Identification of the major urinary metabolite of the F2-isoprostane 8-iso-prostaglandin F2alpha in humans. J Biol Chem 1996, 27I(34):20617-20620.

50. Basu S: Metabolism of 8-iso-prostaglandin F2alpha. FEBS Lett 1998, 428( I-2):32-36.

5I. Ulus AT, Aksoyek A, Ozkan M, Katircioglu SF, Basu S: Cardiopulmonary bypass as a cause of free radical-induced oxidative stress and enhanced blood-borne isoprostanes in humans. Free Radic Biol Med 2003, 34(7):911-917.

52. Zhu X, Raina AK, Perry G, Smith MA: Alzheimer's disease: the two-hit hypothesis. Lancet Neurol 2004, 3(4):219-226.

53. Gasparini L, Ongini E, Wenk G: Non-steroidal anti-inflammatory drugs (NSAIDs) in Alzheimer's disease: old and new mechanisms of action. J Neurochem 2004, 9 I(3):52I-536.

54. Szekely CA, Thorne JE, Zandi PP, Ek M, Messias E, Breitner JC, Goodman SN: Nonsteroidal anti-inflammatory drugs for the prevention of Alzheimer's disease: a systematic review. Neuroepidemiology 2004, 23(4): 159-169.

55. McGeer PL, McGeer EG: NSAIDs and Alzheimer disease: Epidemiological, animal model and clinical studies. Neurobiol Aging 2006.

56. Mirra SS, Heyman A, McKeel D, Sumi SM, Crain BJ, Brownlee LM, Vogel FS, Hughes JP, van Belle G, Berg L: The Consortium to Establish a Registry for Alzheimer's Disease (CERAD). Part II. Standardization of the neuropathologic assessment of Alzheimer's disease. Neurology I991, 4I(4):479-486.

57. Hyman BT, Trojanowski JQ: Consensus recommendations for the postmortem diagnosis of Alzheimer disease from the National Institute on Aging and the Reagan Institute Working Group on diagnostic criteria for the neuropathological assessment of Alzheimer disease. J Neuropathol Exp Neurol 1997, 56(10): 1095-1097.
58. Basu S: Radioimmunoassay of 8-iso-prostaglandin F2alpha: an index for oxidative injury via free radical catalysed lipid peroxidation. Prostaglandins Leukot Essent Fatty Acids 1998, 58(4):319-325.
Publish with Bio Med Central and every scientist can read your work free of charge

"BioMed Central will be the most significant development for disseminating the results of biomedical research in our lifetime. "

Sir Paul Nurse, Cancer Research UK

Your research papers will be:

- available free of charge to the entire biomedical community

- peer reviewed and published immediately upon acceptance

- cited in PubMed and archived on PubMed Central

- yours - you keep the copyright

Submit your manuscript here:

http://www.biomedcentral.com/info/publishing_adv.asp
Biomedcentral 